\title{
Focus Particles Inside Prepositional Phrases: A Comparison of Dutch, English, and German
}

\author{
Gosse Bouma · Petra Hendriks · Jack Hoeksema
}

Received: 17 September 2004 / Accepted: 14 August 2005 / Published online: 14 February 2007 (C) Springer Science+Business Media B.V. 2007

\begin{abstract}
Partly due to disagreement on acceptability judgements, there is little agreement on the possibility of PP-internal and DP-internal focus particles in languages such as Dutch, English, and German. Our large-scale corpus investigation reveals that PP-internal focus particles are a genuine possibility, not only in English, but also in Dutch and, to a lesser extent, German. These results seem to be incompatible with a number of existing syntactic theories of bound focus in German. However, our investigation also provides evidence for a strong dispreference for focus particles to follow a preposition, although the dispreference is less strong in Dutch than in German. Qualitative analysis of the corpus data shows that the variational patterns found in English, Dutch, and German are highly similar, and are influenced by lexical-semantic as well as syntactic factors. We sketch an alternative analysis, couched in the framework of stochastic Optimality Theory.
\end{abstract}

Keyword Corpus analysis · Focus particles · Optimality Theory · Prepositional phrases $\cdot$ Word order variation

\section{Introduction}

The conduct of comparative work in Germanic linguistics, as elsewhere, raises the issue of how to deal with cross-linguistic variation. A popular approach

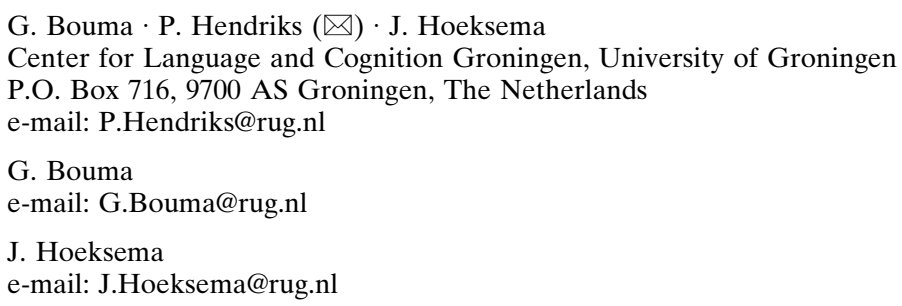


within the generative paradigm is the parametric approach to micro-variation, which relates patterns of variation to different settings of syntactic or other parameters. An alternative to this approach is offered by Optimality Theory (OT), namely constraint re-ranking. We will argue that current approaches to the placement of focus particles in West-Germanic, in particular English and German, are more successful in bringing out the differences than in highlighting the equally striking similarities between these languages. After presenting some of the main approaches to the problem of focus particles in prepositional phrases, and providing corpus data which allow for more refined comparisons between the languages than were hitherto available, we sketch an alternative, couched in the framework of stochastic OT, which captures both similarities and differences among these two languages, and moreover can deal with Dutch, which is in many respects intermediate between German and English, in a natural way.

\section{An empirical issue}

While focus particles may appear in a wide variety of environments, their distribution is not unrestricted. There appears to be general agreement in the literature on two distributional properties of focus particles:

- Focus particles must attach to maximal projections (XPs)

- Focus particles must c-command the focused phrase. ${ }^{1}$

In addition to these two restrictions, some further constraints have been proposed in the literature, but as to the precise nature of these additional constraints, there is little agreement, partly due to disagreement on acceptability judgements. Areas of disagreement involve prepositional phrases and genitive constructions in English and German. In this paper, we propose to resolve this disagreement on the basis of large-scale corpus data. But before doing so, we briefly survey four key analyses: Jacobs (1983), Rooth (1985), Bayer (1996), and Büring and Hartmann (2001). For each theory, we summarize the predictions it makes for the possibility of PP- and DP-internal focus particles. Various other interesting aspects of particle distribution, such as particles adjoined to postverbal or extraposed constituents, will not be dealt with in this paper.

\footnotetext{
${ }^{1}$ We assume Reinhart's (1976) definition of c-command: A c-commands B iff every node C that dominates $\mathrm{A}$ also dominates $\mathrm{B}$. We are aware of one important exception to the c-command requirement: additive focus particles, which may follow their focus associate (cf., e.g., Hoeksema \& Zwarts, 1991 on Dutch ook and English even, or Reis \& Rosengren, 1997 on German auch), and need not always c-command it. Compare the contrast between (i), where even is associated with the focused subject, and (ii), where the same is attempted for the nonadditive particle only:
}

(i) The POPE will even grant you this

(ii) *The POPE will only grant you this. 


\subsection{Jacobs (1983)}

In Jacobs' (1983) GPSG account of bound focus in German, focus particles attach to some projection of $\mathrm{V}$ in cases where the particle takes scope over a proposition. This assumption allows for a rule-by-rule translation of syntactic configurations into model-theoretic objects. The sentence is taken to be the maximal projection of $\mathrm{V}$. This goes against a common assumption in the literature that the focus particle is attached to the DP in examples such as (1) below:
(1) daß Luise [nur [ihrem Arzt]] ein Auto vermachte. that Luise only her doctor a car donated
'that Luise donated a car only to her doctor.'

Jacobs, on the other hand, assumes that nur 'only, just' is left-adjoined to the verbal projection:

(1') daß Luise [nur [ihrem Arzt ein Auto vermachte]]

Jacobs motivates his claim that nur attaches only to projections of $\mathrm{V}$ by noting that it explains why focus particles may not appear inside PPs or attached to postnominal genitives (i.e., DP-internally). Compare the following examples (Jacobs' judgements):

(2) *Peter träumt von nur seiner Frau.

Peter dreams of only his wife

'Peter only dreams of his WIFE.'

(3) *Den Sohn nur des Grafen liebt sie. the son only of-the count loves she

'She only loves the son of the COUNT.'

A direct consequence of Jacobs' analysis is that the familiar generalization must be abandoned that in German root sentences the finite verb appears in second position (the so-called V2 property of many Germanic languages). If focus particles attach to $\mathrm{V}$-projections, nur in (4) below must be attached to the entire sentence:

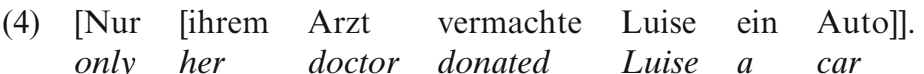

'Only her doctor donated Luise a car

'Only to her doctor did Luise donate a car.'

But according to this parsing, not one, but two constituents precede the finite verb: nur and ihrem Arzt. Bayer (1990) and Hoeksema (1989) have viewed this aspect of Jacobs' analysis as highly problematic, since it is directly at odds with one of the strictest word-order constraints of German. Moreover, it was noted by these authors that Jacobs' account fails to predict that in sentences 
such as (4), focus can only be on the initial DP ihrem Arzt. If, on the other hand, it is assumed that nur is adjoined to ihrem Arzt, this property would follow from a simple c-command requirement on the association with focus (cf. the beginning of this section), and the exception to V2 could be eliminated. However, that still leaves the PP and genitive data that gave rise to Jacobs' theory to account for.

\subsection{Rooth (1985)}

Rooth (1985) proposes a semantic theory of association with focus. Under his account, association between the focus particle and the focused phrase is the result of application of the denotation of the focus particle to the denotation of a lambda-abstracted verb phrase. Rooth's theory accounts for the same data that are captured by a movement theory of association with focus (according to which the focused phrase moves at LF, cf. Chomsky, 1976 for an early proposal) while avoiding the problems that are known to be associated with such a movement theory, in particular the insensitivity of association with focus to syntactic islands. According to Rooth's account, which is primarily directed at English, only can adjoin to VP and DP, whereas even can adjoin to $\mathrm{S}$ as well. If only or even adjoins to DP, the result is a quantified DP, which can be expected to undergo Quantifier Raising (QR).

Problematic for Rooth's account, as he himself acknowledges, are examples such as the following (judgements are Rooth's):

(5) a. ? At the party, John spoke to only Mary.

b. * The children play in only the common.

c. * The library is closed on only Sunday.

d. * They joked about even the flood.

(6) a. * The entrance only to the Santa Monica freeway was blocked off.

b. * The entrance to only the Santa Monica freeway was blocked off.

c. * The entrance even to the Santa Monica freeway was blocked off.

d. ? The entrance to even the Santa Monica freeway was blocked off.

Since Rooth permits focus particles to freely adjoin to DP constituents, the above PP- and DP-internal occurrences ought to be completely acceptable.

\subsection{Bayer (1996)}

According to the analysis in Bayer (1996), the distribution of focus particles follows from the fact that they are (at least in some cases) scope-bearing elements. Scope-bearing elements are subject to QR at Logical Form (LF) where they are assigned scope. QR is a movement rule, and as such subject to various syntactic island constraints. As an effect, focus particles are barred from certain syntactic positions. For instance, in German PPs there is a clash between the demands of scope-taking and the limitations imposed by syntactic 
islands. Bayer argues that this explains why non-scalar focus particles such as nur 'only' and sogar 'even' may not intervene between P and DP. ${ }^{2}$ Compare the difference in acceptability between (7) and (8):

(7) daß sie nur mit dem OPA that she only with the granddaddy chats 'that she only chats with GRANDDADDY.'

(8) * daß sie mit nur dem OPA that she with only the granddaddy chats 'that she only chats with GRANDDADDY.'

A similar problem appears to exist in German genitive constructions. This contrasts with the situation in English, where both PP- and DP-internal focus particles are acceptable, according to Bayer. Bayer questions Rooth's (1985) judgements on the English examples in (5) and (6) above:

In order to see more clearly how the data actually pattern, I asked native speakers of English to judge these sentences. Given the usual minor variations, the result did not conform to Rooth's judgements. Many speakers are willing to accept not only the ? - marked sentences, but also some of those which according to Rooth should be completely ungrammatical. Taglicht (1984: 4.2.4.) gives similarly negative judgements on focusing particles inside PPs, but then has to admit (see footnote 29 , pp. 96f.) that " 'resistance' to narrow focus on non-scalar items is not uniform for different speakers or for different items." Notice furthermore that in Ross and Cooper (1979) one finds the examples in (58) without a mark on them:

(58) a. They are sending eggs to even MARIE.

b. They are sending eggs to only MARIE.

[..] What is important at this point is that there seems to be a significant difference between English and German in that the former allows particles focusing on an entire DP inside PP, at least as a marked option, while the latter language strictly bans such occurrences.

(Bayer, 1996, p. 32)

In fact, the claimed difference in behavior of focus particles inside PPs in German and English constitutes Bayer's main argument against Rooth's analysis. According to Bayer, this difference suggests that a movement

\footnotetext{
${ }^{2}$ Scalar particles are allowed in PP-internal position (cf. Bayer, 1996; Jacobs, 1983):

(i) in nur zwei Minuten in just two minutes
}

This is because scalar particles quantify locally, and do not take scope at a higher operator position, according to Bayer (1996, pp. 61ff). 
account should be preferred to a semantic account. Bayer relates this difference between German and English to the possibility of preposition stranding in the latter language. Because German does not allow for preposition stranding, it must be assumed that PPs are islands for movement. Hence the focus particle cannot move at LF to a higher position outside the PP where it can be assigned scope. This accounts for the unacceptability of (8) above. English, on the other hand, permits extraction out of PPs, and thus sentences such as (5a) are predicted to be acceptable. Note that since Bayer links the option of PP-internal focus particles to the possibility of preposition stranding, he predicts that languages such as Dutch, which pattern like German with respect to preposition stranding, should likewise bar PP-internal focus particles. As Hoeksema and Zwarts (1991) and Hoeksema (1999) have argued, however, PP-internal focus particles are sometimes possible in Dutch, and so this prediction seems to be too strong. See also below for more discussion of the Dutch data.

\subsection{Büring and Hartmann (2001)}

Büring and Hartmann (2001) propose a variant of Jacobs' (1983) account. They argue that German focus particles can be adjoined to non-arguments only. Focus particles cannot be adjoined to DP or CP arguments, in their account, but as adverbial elements they can be adjoined to non-argument CPs, IPs, and VPs. Their first and central argument for this position is Jacobs' original observation that DP- and PP-internal focus particles are unacceptable. They also present a new and interesting argument, based on reconstruction effects. Büring and Hartmann point out that topicalized objects can be reconstructed in their base position. In the predominant reading of (9) below, the direct object einen Fehler takes scope below the subject jeder, giving rise to the reading indicated:

$\begin{array}{llllll}\text { (9) }[\text { Einen } & \text { Fehler }]_{\mathrm{i}} & \text { hat } & \text { vermutlich jeder } & \mathrm{t}_{\mathrm{i}} & \text { gemacht. } \\ a & \text { mistake } & \text { has presumably everybody } & \mathrm{t}_{i} & \text { made }\end{array}$

'Presumably everyone made some mistake.'

Sentences in which the topicalized object is preceded by a focus particle, as in (10) below, do not have an interpretation in which the focus particle has scope below the subject. The predominant reading of (10) is 'Only Maria is loved by everyone' and not 'Everyone loves only Maria':

$\begin{array}{lll}\text { Nur MARIA liebt jeder } & \mathrm{t}_{\mathrm{i}} . \\ \text { only Maria loves everyone } & \mathrm{t}_{i} \\ \text { 'Only Maria is loved by everyone.' } & \end{array}$

\footnotetext{
${ }^{3}$ One of our reviewers has noted that with the right intonation, involving stress on jeder, example (10) becomes ambiguous, allowing for a narrow scope reading of nur Maria as well as a wide scope reading. See also Reis (2005) for similar examples bearing on this issue. We take this to be further evidence for our general position that the account given by Büring and Hartmann is on the wrong track.
} 
According to Büring and Hartmann, this shows that the focus particle and the object do not form a constituent. In sentences beginning with the string PRT$\mathrm{DP}$, the focus particle in fact adjoins to the root CP, thus allowing V3. To account for the fact that in sentences like (10), focus can only be on the preverbal constituent, Büring and Hartmann propose the Closeness Principle, which says that focus particles should be maximally close to the focus. Therefore, when focus is on a constituent in the middle field, the focus adverb should also appear in the middle field. While we believe that the Closeness Principle might play a role in the preferential placement of focus particles in the middle field, we do not think it really explains the hard facts of sentenceinitial occurrences. In the middle field, we find that although closeness of the particle to the focus item might be preferred, it is certainly not an absolute requirement. Cf. the following naturally-occurring example: ${ }^{4}$

(11) Denn Kei liebt Mizuho-Sensei nicht nur, er ist sogar mit ihr verheiratet. for Kei loves Mizuho-Sensei not only, he is even with her married 'For Kei not only loves Mizuho-Sensei, he is even married to her.'

Note that the Closeness Principle would force the variant in (12), which, to be sure, is also acceptable. The point is, though, that (11) is just as good.

(12) Denn Kei liebt Mizuho-Sensei nicht nur, er ist mit ihr sogar verheiratet. for Kei loves Mizuho-Sensei not only, he is with her even married 'For Kei not only loves Mizuho-Sensei, he is even married to her.'

In light of this, we fail to see how the Closeness Principle could explain the much more strictly enforced constraint that sentence-initial focus particles always select the preverbal element as their focus partner.

Regarding English, Büring and Hartmann stipulate that adnominal particles are possible in that language, though they are not in German. In this way, they predict that PP- and DP-internal focus particles should be possible in English but not in German.

To summarize: Rooth (1985) as well as Bayer (1996) predict PP- and DPinternal focus particles to be fully acceptable in English. Büring and Hartmann (2001) also suggest the possibility of PP- and DP-internal focus particles in English. However, as Rooth notes, cases of PP- and DP-internal focus particles appear to be marginal or impossible in English (cf. Taglicht, 1984). Rooth's judgements with respect to these cases have been questioned by Bayer, though. Regarding German, Jacobs (1983), Bayer (1996), and Büring and Hartmann (2001) all claim that PP- or DP-internal focus particles are completely impossible. According to Bayer (1996), PP-internal focus particles in German are just as unacceptable as preposition stranding in this language. Although none of these accounts explicitly addresses Dutch, Bayer's predictions for German should carry over to Dutch, since Dutch patterns like German with respect to preposition stranding. However, problematic for

\footnotetext{
${ }^{4}$ From: http://www.jasms.de/anime/onegai_teacher/ot_start.html.
} 
Bayer's analysis is the observation made by Hoeksema and Zwarts (1991) and Hoeksema (1999) that PP-internal focus particles are sometimes possible in Dutch.

\section{Corpus data: Possibility and likelihood of PP-internal focus particles}

We have seen above that there is considerable disagreement on quite a simple matter: the possibility of PP-internal and DP-internal focus particles in languages such as Dutch, English, and German. It should in principle be relatively simple to resolve the issue by looking at corpus data, since we only have to verify whether or not certain strings of words are possible. As we will see, mere possibility is indeed a straightforward matter, ${ }^{5}$ but things become more complex when we consider not just possibility, but also likelihood.

\subsection{Dutch}

Let us start with a look at Dutch. Using a 78-million-word newspaper corpus (the 1994 and 1995 editions of the Algemeen Dagblad and NRC Handelsblad), we found a considerable number of cases where prepositions were followed by a focus particle, some of which we list below:

a. Voor de ouderen met alleen een AOW-uitkering stijgt
for the elderly with only a AOW allowance rises
dan het netto-inkomen.
then the net income
'For the elderly with only an old-age pension, net income will rise then.'
b. Zonder toestemming gebruikmaken van alleen de namen van
without permission using of only the names of
voetballers en topsporters mag evenmin.
soccer.players and sports.stars may neither
'Making use of just the names of soccer players and sports stars
without permission is not allowed either.'
c. Bovendien hebben we de komende weken een druk programma,
besides have we the coming weeks a busy programme
met ook doordeweekse wedstrijden.
with also weekday games
'Besides, we have a busy programme in the coming weeks, with weekday
games as well.'
d. De gevolgen kunnen variëren van depressies en echtscheidingen
the effects can vary from depressions and divorces

\footnotetext{
${ }^{5}$ As an anonymous reviewer pointed out, such a corpus study has been carried out before, with similar conclusions (cf. Barbiers, 2003a, b). However, the present study has several advantages, including a more fine-grained differentiation of focus particles and prepositions, and a qualitative as well as quantitative approach. 
tot zelfs suïcide.

to even suicide

'The consequences may vary from depressions and divorces to suicide even.'

The above examples are all acceptable to the ear of each of the co-authors of this paper, and therefore cannot be discarded as performance errors. We conclude that PP-internal focus particles are a genuine option in Dutch.

To gain more insight into the relative frequency of PP-internal focus particles, we collected all examples from the corpus. To this end, the corpus was parsed automatically using the Alpino system, a linguistically-motivated, wide-coverage parser for Dutch (Malouf \& van Noord, 2004; van der Beek, Bouma, \& van Noord, 2002). The parser produces dependency trees, in which we may search for all PP-internal occurrences of focus particles immediately dominated by a PP-node (P-Adv-NP strings) and for all occurrences of a focus particle preceding the PP (Adv-P-NP strings). The results are shown in Tables 1-3.

In Table 1, we note for van 'of' a relatively high percentage $-21 \%$ of occurrences-of PP-internal alleen 'only'. This is due to a syntactic factor: of the first 20 occurrences of the order van alleen de, all 20 were cases of PPs inside a larger nominal phrase, whereas of the first 20 occurrences of alleen van de, all 20 were cases of PPs that did not form part of a larger NP. The relatively high percentage of $\mathrm{P}-\mathrm{Adv}-\mathrm{NP}$ orders for $\mathrm{P}=$ van may then simply be a reflection of the fact that van-PPs are nominal modifiers more often than other PPs are. As was noted in, e.g., Bayer (1990, 1996), focus particles do not adjoin to adnominal PPs; cf., e.g., the following Dutch examples (judgements are ours):

$\begin{array}{llll}\text { a. alleen de } & \text { vrienden van MABEL } \\ \text { only the friends of } & \text { MABEL }\end{array}$

Table 1 Preposition + alleen bigrams

\begin{tabular}{lcc}
\hline P-alleen & P-Adv-NP & Adv-P-NP \\
\hline met 'with' & $412(32 \%)$ & $889(68 \%)$ \\
van 'of' & $86(21 \%)$ & $321(79 \%)$ \\
voor 'for, before' & $30(2 \%)$ & $1389(98 \%)$ \\
tot 'until' & $12(12 \%)$ & $92(88 \%)$ \\
door 'through/by' & $11(2 \%)$ & $642(98 \%)$ \\
in 'in' & $11(0.4 \%)$ & $2442(99.6 \%)$ \\
op 'up, above' & $11(1 \%)$ & $1091(99 \%)$ \\
in plaats van' 'instead of' & $10(91 \%)$ & $1(9 \%)$ \\
\hline
\end{tabular}

* In Table 1, we have treated the string in plaats van 'instead of' as a complex preposition. The fact that it strongly prefers the order P-Adv-NP is of course in line with our observation in this section about the behavior of van in complex noun phrases 
Table 2 Preposition + ook bigrams

\begin{tabular}{lcc}
\hline P-ook & P-Adv-NP & Adv-P-NP \\
\hline met 'with' & $49(2 \%)$ & $2962(98 \%)$ \\
van 'of' & $39(1.4 \%)$ & $2638(98.6 \%)$ \\
in 'in' & $6(0.04 \%)$ & $13641(99.96 \%)$ \\
voor 'for/before' & $5(0.1 \%)$ & $6485(99.9 \%)$ \\
tot 'until' & $4(0.5 \%)$ & $797(99.5 \%)$ \\
tegen 'against' & $3(0.5 \%)$ & $560(99.5 \%)$ \\
om 'around' & $3(0.5 \%)$ & $654(99.5 \%)$ \\
over 'over' & $3(0.2 \%)$ & $1451(99.8 \%)$ \\
aan 'on, to' & $3(0.2 \%)$ & $1883(99.8 \%)$ \\
\hline
\end{tabular}

Table 3 Preposition + zelfs bigrams

\begin{tabular}{lcc}
\hline P-zelfs & P-Adv-NP & Adv-P-NP \\
\hline van 'of' & $51(10 \%)$ & $455(90 \%)$ \\
tot 'until' & $33(9 \%)$ & $315(91 \%)$ \\
met 'with' & $26(3 \%)$ & $788(97 \%)$ \\
voor 'for/before' & $9(1.4 \%)$ & $644(98.6 \%)$ \\
in 'in' & $4(0.3 \%)$ & $1517(99.7 \%)$ \\
om 'around' & $3(6 \%)$ & $50(94 \%)$ \\
\hline
\end{tabular}

$\begin{array}{cllll}\text { b. *de } & \text { vrienden } & \text { alleen } & \text { van } & \text { MABEL } \\ \text { the } & \text { friends } & \text { only } & \text { of } & \text { MABEL } \\ \text { c. ?de } & \text { vrienden } & \text { van } & \text { alleen } & \text { MABEL } \\ \text { the } & \text { friends } & \text { of } & \text { only } & \text { MABEL }\end{array}$

This suggests that cases of PP- and DP-internal focus particles, which are still too often grouped together in the literature (see Sect. 2), should be distinguished. In general, focus particles are allowed to occur PP-internally as well as PP-externally in Dutch. In these cases, PP-external occurrence (outside adjunction of the focus particle to the PP) is preferred to PP-internal occurrence. However, if the PP is a postnominal genitive or other postnominal modifier, i.e., if the focus particle occurs DP-internally, outside adjunction to the PP is ruled out for independent reasons. As a result, PP-internal focus particles and DP-internal focus particles have different distributional patterns.

The bigram data presented in Tables 1-3 show considerable variation among prepositions and among focus particles. However, this is not all. When we look at a much larger corpus, the Dutch part of the World Wide Web, we find even more parameters of variation. Not only is there considerable lexical variation among prepositions and focus particles, but the initial member of the DP also plays a role in determining the position of the focus particle. In Table 4, we have used Google counts of June 17, 2005, as an informal estimate 
Table 4 Google counts for the Dutch three-word string met-alleen-Det versus alleen-met-Det

\begin{tabular}{|c|c|c|c|c|}
\hline P-Adv-X & $N$ & Adv-P-X & $N$ & $\%$ P-Adv-X \\
\hline $\begin{array}{l}\text { met alleen de } \\
\text { 'with only the' }\end{array}$ & 800 & alleen met de & 835 & $49 \%$ \\
\hline $\begin{array}{l}\text { met alleen die } \\
\text { 'with only that' }\end{array}$ & 502 & alleen met die & 726 & $41 \%$ \\
\hline $\begin{array}{l}\text { met alleen deze } \\
\text { 'with only this' }\end{array}$ & 210 & alleen met deze & 498 & $30 \%$ \\
\hline $\begin{array}{l}\text { met alleen mijn } \\
\text { 'with only my' }\end{array}$ & 442 & alleen met mijn & 715 & $38 \%$ \\
\hline $\begin{array}{l}\text { met alleen onze } \\
\text { 'with only our' }\end{array}$ & 105 & alleen met onze & 591 & $15 \%$ \\
\hline $\begin{array}{l}\text { met alleen uw } \\
\text { 'with only your' }\end{array}$ & 189 & alleen met uw & 744 & $20 \%$ \\
\hline $\begin{array}{l}\text { met alleen mannen } \\
\text { 'with only men' }\end{array}$ & 122 & alleen met mannen & 147 & $45 \%$ \\
\hline $\begin{array}{l}\text { met alleen vrouwen } \\
\text { 'with only women. }\end{array}$ & 202 & alleen met vrouwen & 249 & $45 \%$ \\
\hline $\begin{array}{l}\text { met alleen geld } \\
\text { 'with only money' }\end{array}$ & 41 & alleen met geld & 367 & $10 \%$ \\
\hline
\end{tabular}

of frequency on the World Wide Web of a number of three-word strings. To avoid fluctuations due to the fact that some texts appear many times on the Internet, we made use of the Google option of omitting 'similar entries'. 6

Although for almost every string we checked there is a preference for the Adv-P-X order over the P-Adv-X order, this preference is sometimes very slight. There are robust and surprising differences between definite articles and demonstratives, and, among demonstratives, between distal and proximal cases. Equally interesting are the differences among the words for men and women on the one hand, and the word for money on the other.

The robust attestation of the P-Adv-X order in prepositional groups headed by met 'with', compared to other prepositions, has to be seen, in our view, as a consequence of scopal differences between the P-Adv-X and the Adv-P-X order that are specific to met-phrases. Consider, for instance, the following sentences:
$\begin{array}{llllll}\text { a. Met alleen mannen ga } & \text { niet } \\ \text { with only men } & \text { go } I \text { not out }\end{array}$
'I'm not going out with just men.'

\footnotetext{
${ }^{6}$ We are well aware of the current controversy over the accuracy of Google counts. We refer the reader to the Technologies du language blog by Jean Véronis (http://www.aixtal.blogspot.com/). We have only counted strings and have avoided the especially problematic use of Boolean operators. Moreover, the numbers of hits that we found in each category are sufficiently large to establish our main findings.
} 


\section{b. Alleen met mannen ga ik niet uit. only with men go I not out 'Only with men do I not go out.'}

Clearly, the two statements are not equivalent, and should therefore not be viewed as syntactic variants. In (15a), the focus particle alleen does not take scope over the preposition met, in contrast to (15b). ${ }^{7}$ Example (15a) has a prominent group reading, which is absent in (15b), according to which I am not going out with any group of people consisting solely of men. Example (15b) on the other hand has the distributive reading that can be paraphrased as 'Only men belong to the category of people I do not go out with.' Extralinguistic factors will determine how often PP-internal scope is relevant for various kinds of strings. For instance, in the case of men and women, it is often considered important whether groups consist of just men or just women. With other nouns, such as geld 'money', we get a lower percentage of P-Adv-X strings, presumably because here the PP-internal reading is less often relevant.

As regards the clear difference between distal die and proximal deze in Table 4, there is a straightforward explanation: die may be used to introduce restrictive relative clauses, unlike deze: compare die studenten die ... 'those students who ...' with *deze studenten die ... 'these students who ...'. In a small sample of 20 occurrences of the string met alleen die, 9 were cases of die introducing a relative clause. This difference is important because of a number of conspiring factors. Prepositional phrases containing a relative clause are more likely in Dutch to be extraposed as a whole than shorter prepositional phrases (a standard heaviness effect; cf., e.g., Behaghel's (1932) Gesetz der wachsenden Glieder, noted in Shannon's (1995) corpus study of extraposition

\footnotetext{
${ }^{7}$ An anonymous reviewer suggested that in PPs introduced by met 'with', we are dealing with a small-clause structure, in which PP-internal alleen has narrow scope. We believe such an analysis is indeed appropriate for so-called absolute met (exemplified, e.g. by met de hele klas ziek 'with the whole class sick'), but we do not think it is correct for all cases. Absolute constructions are never verbal arguments, but always optional adjuncts. However, even in met-PPs that are clearly selected by some verb, we find occurrences of PP-internal alleen such as the following (taken from http://www.demolenaar.nl/...).
}

(i) Het herziene koemodel houdt juist geen rekening met alleen VEM-waarde the revised cow.model keeps just no account with only VEM value maar met de gehele chemische samenstelling (tabel 2). but with the entire chemical composition (table 2)

'The revised cow-model does not just consider the VEM value, but the entire chemical composition.'

We are not aware of any evidence that met-phrases in expressions such as rekening houden met 'reckon with, consider' may ever contain small clauses. Sentences such as (ii) are blatantly ungrammatical:

(ii) * We houden rekening met de hele klas ziek. we keep account with the whole class sick 
in Dutch and German). Extraposed expressions may not have focus particles adjoined to them (cf. Hoeksema, 1989, p. 119): ${ }^{8}$
a. Ik ga alleen in JUNI waterskiën. I go only in June water.ski 'I am only going to go water ski in June.'
b. Ik ga alleen waterskiën in JUNI.
c. *Ik ga waterskiën alleen in JUNI.

Compare also the following variants of the examples in (15):

(17) a. Ik ga niet uit met alleen mannen.
I go not out with only men
'I'm not going out with men only.'
b. * Ik ga niet uit alleen met mannen.

In (17b), the focus particle is adjoined to the extraposed PP. Together, a preference for extraposing PPs with relative clauses and the dispreference for adjoined particles on extraposed PPs help explain why the distal demonstrative die is more commonly found in P-Adv-Det strings than its proximal counterpart deze. The fact that relative clauses were found in almost half of the Google hits involving the string met alleen die and in none of the hits involving met alleen deze squares nicely with the fact that the P-Adv-Det order is about twice as common when the determiner is die rather than deze. If we were to remove all cases involving relative clauses, the two percentages would be identical.

Another striking observation to be found in Table 4 is the rather high percentage of alleen met mijn 'only with my', compared to other possessive determiners. This turns out to be due to the lexical ambiguity of alleen, which can be the counterpart of the adjective alone or that of the adverb only. The relatively high frequency of alleen met mijn is due to more cases of the "alone with my'-reading ("I want to be alone with my sorrow", "She left me alone with my gameboy", etc.).

The variation among these prepositions is substantial. We have already commented on the special status of van. Here, the variation is entirely due to a syntactic factor: of the first 20 occurrences of the order van alleen de, all 20 were cases of PPs inside a larger nominal phrase, whereas of the first 20 occurrences of alleen van de, all 20 were cases of PPs that did not form part of a larger noun phrase.

To conclude: in Dutch, there is considerable variation as regards the preferences for Adv-P-X order versus P-Adv-X order, some having to do with

\footnotetext{
${ }^{8}$ In German, the situation is slightly more complex, since it allows for outside focus particles on extraposed clausal PPs, cf. Bayer (1996, p. 204), as exemplified by the bracketed material in (i):

(i) daß Hans hereingekommen wäre [nur wenn alle geschlafen hätten]. that Hans entered be only when all slept had 'that Hans would have entered only if everybody were asleep.'
} 
Table 5 Cosmas II counts for German mit-nur-Det versus nur-mit-Det

\begin{tabular}{lllll}
\hline P-Adv-Det & $N$ & Adv-P-Det & $N$ & \% P-Adv-Det \\
\hline mit nur dem & $3(7)$ & nur mit dem & 4,425 & 0.07 \\
mit nur der & $0(15)$ & nur mit der & 3,639 & 0 \\
mit nur diesem & $3(4)$ & nur mit diesem & 184 & 1.6 \\
mit nur dieser & 0 & nur mit dieser & 155 & 0 \\
\hline
\end{tabular}

pragmatic/lexical semantic factors (the difference between mannen/vrouwen 'men/women' on the one hand and geld 'money' on the other) and some with syntactic factors (possibility of relative clauses, no external particles in extraposition).

\subsection{German}

German differs significantly from English, but also, more surprisingly, from Dutch. Compare for example the results in Table 5 with those in Table 4. Whereas in Dutch the dispreferred order P-Adv-Det still accounts for about $22 \%$ of the data in the special case of the preposition met, in German this percentage drops to $0.07 \%$ for the lexical counterpart mit. The data in this table are from the corpus of written German of the Institut für Deutsche Sprache in Mannheim, and were accessed through the Cosmas II interface. According to the IDS, this corpus consists at the moment of nearly 2 billion words, and is therefore considerably larger than the Dutch and English corpora that we used. The numbers in brackets are the raw scores given by Cosmas II, and the non-bracketed numbers are the scores after irrelevant data were discarded after inspection, such as cases where the string was interrupted by a period, or cases where a scalar interpretation of nur was involved.

One might suspect that the small percentages for P-Adv-Det are explained by the fact that this order is ungrammatical, and that the sporadic occurrences of this word order in the German corpus are due to performance errors. However, we don't think that the occurrences we found are mere noise. Rather, we suspect that they reflect an option that is grammatical at least for some users of German. The following examples, taken from the Internet and the IDS corpus, respectively, are illustrative of the kind of occurrences that we have found:

(18) Wahlweise kann man sich die Maschine mit nur dem optionally can one REFL the machine with only the Piloten oder 1-3 pilot or 1-3 


\section{Passagieren auswählen und kommt damit praktisch auf 8 passengers select and comes thus practically at 8 verschiedene Varianten. ${ }^{9}$ different variants \\ 'Optionally, one may select the plane with only the pilot or 1-3 passengers, thus arriving at eight different variants.'}
Der Stadtrat hat am Dienstag vergangener Woche bei einer the city.council has on Tuesday last week during a

Sitzung mit nur diesem Tagesordnungspunkt ein Ansuchen um eine meeting with only this agenda item a request for a Bordellbewilligung einstimmig abgelehnt. ${ }^{10}$ brothel.permit unanimously denied 'The city council denied a request for a brothel permit on Tuesday last week in a meeting with only this agenda item.'

The $\mathrm{P}-\mathrm{Adv}$-Det option is not just limited to the case where $\mathrm{P}=$ mit, but can be attested for other choices of prepositions as well:

Symbol: Zeigt Ihnen die ganze Ziffer an oder reduziert die
Symbol: Shows you the whole number PRT or reduces the
Auswahl auf nur diese Ziffer.
choice to only this number

In spite of the rarity of the P-Adv-Det order in German, there is no need for ruling it out as grammatically incorrect. German and Dutch have essentially the same grammatical structure with respect to the issues at hand, and the only difference amongst them, in our view, is that an order which is disfavored in Dutch, is even more strongly disfavored in German.

\subsection{English}

Since hardly anyone disputes that English allows for focus adverbs inside prepositional phrases, we will refrain from arguing this point. What we will

\footnotetext{
${ }_{9}$ This example was taken from: http:// www.flightxpress.de/artikel/0602/archer/archer.html. An anonymous reviewer makes the point that even example (18) could be viewed as scalar in nature, given that a plane "can be rented under different conditions of size of manning of which the pilot alone is the smallest possible size." If we treat such examples as scalar, on a par with cases like only a few or only one, we run into the problem that all expressions of the form only $N P$, such as only John, or German nur Hans, are technically to be treated as scalar, since any singular definite description pinpoints an atom of a lattice of sets (cf., e.g., Link, 1983), and can therefore be viewed as a scalar endpoint of the 'scale' (or rather: partial order) of all groups containing the atom. The consequence would be that we are completely at a loss, then, why German, which allows for scalar PP-internal focus adverbs, only very rarely allows for PP-internal occurrences of nur NP, where NP is a singular definite NP. We must therefore reject the suggestion by the reviewer.

${ }^{10}$ Tiroler Tageszeitung, August 2, 2000 (included in the written German corpus of the Institute for German language in Mannheim).

${ }^{11}$ From: http://www.norm.energycodes.ch/page.asp?DH $=15$.
} 
Table 6 BNC counts for English P-only-the versus only-P-the

\begin{tabular}{lllll}
\hline P-Adv-Det & $N$ & Adv-P-Det & $N$ & $\%$ P-Adv-Det \\
\hline with only the & 186 & only with the & 319 & $36.8 \%$ \\
for only the & 44 & only for the & 476 & $8.5 \%$ \\
in only the & 19 & only in the & 1213 & $1.5 \%$ \\
by only the & 8 & only by the & 545 & $1.4 \%$ \\
of only the & 24 & only of the & 251 & $9 \%$ \\
to only the & 10 & only to the & 655 & $1.5 \%$ \\
\hline
\end{tabular}

show is that the variational patterns found in English are actually very similar to those found in Dutch and, to a lesser extent, German. For example, the preposition with differs from other prepositions in more readily and frequently allowing for the P-Adv-Det order, as Table 6 shows. The data in this table are taken from the British National Corpus, a corpus consisting of 100 million words. $^{12}$

Quite generally, the order P-Adv-Det is dispreferred, just as it is in Dutch and German. The preposition of is similar to with in showing relatively high percentages for the order P-Adv-Det, much the same as its Dutch counterpart van. And presumably the same account given above for van also applies here: external focus particles are generally favored, but not if the PP is itself part of a larger noun phrase. $O f$-phrases are more commonly used as adnominal PPs, than PPs introduced by for or in.

Another similarity between English and its continental relatives is revealed when we vary the focus adverb, as Table 7 shows.

In Table 7, the odd man out is also. This is actually fairly simple to explain: unlike only and even, English also (unlike its German counterpart auch or Dutch ook, which may assume scalar readings, equivalent to even, when combined with superlatives) is never scalar. With quite a few-though by no means all-of the occurrences of in only the and in even the counted by Google, we were actually dealing with scalar cases such as in even the hardest cases. These have always been seen as special cases (Bayer, 1996; Jacobs, 1983; Kayne, 2000; König, 1991), and as much more likely to appear in PP-internal position. ${ }^{13}$ For also, a scalar use is not available (König, 1991), and the result is a much more striking difference in frequency between the two orders.

\section{Approximating adverbs inside and outside PPs: A case of variation and change}

The type of variation in word order between Adv-P-Det and P-Adv-Det discussed above is not restricted to focus adverbs. Similar observations can be

\footnotetext{
${ }^{12}$ For accessing these data, we have used the Web interface provided by Mark Davies of Brigham Young University (http://www.view.byu.edu/).

${ }^{13}$ Possibly because the scalar focus adverbs can attach directly to complex determiners such as the slightest (as suggested by Jacobs, 1983) and therefore escape any conditions on focus particles that adjoin to noun phrases.
} 
Table 7 Google counts for English in-Adv-the versus Adv-in-the

\begin{tabular}{lllll}
\hline in-Adv-the & $N$ & Adv-in-the & $N$ & $\%$ in-Adv-the \\
\hline in only the & 19 & only in the & 1213 & $1.5 \%$ \\
in even the & 49 & even in the & 1380 & $3.4 \%$ \\
in also the & 0 & also in the & 550 & $0 \%$ \\
\hline
\end{tabular}

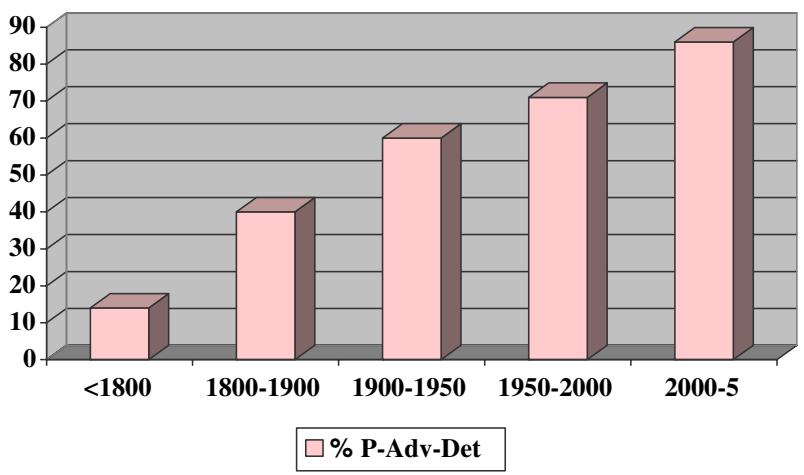

Fig. 1 Percentages of P-Adv-Det order for approximative adverbs

made about a rather different group of adverbial modifiers, the so-called approximative adverbs like almost, nearly, virtually, etc., which tend to co-occur with a proper subset of the determiners (cf. Klein, 1998). In particular universal, negative, and superlative determiners may be preceded by such adverbs: almost all students, nearly every week, virtually anything, almost the last thing. When these determiners are embedded in PPs, word order variation arises: almost in all cases versus in almost all cases. In a large database of Dutch adverbial expressions, collected by Hoeksema from written sources and computer corpora with the help of a number of associates, ${ }^{14}$ a striking trend was noted: from primarily PP-external combinations, to predominantly PP-internal combinations. Table 8 shows the emerging preference for P-AdvDet over a period of three centuries, and Fig. 1 presents the same data in the form of percentages of P-Adv-Det order. It is clear that the change in question is close to completion.

Because Hoeksema's database contains more data from recent periods than from earlier periods, we have chosen to make a subdivision into periods of differing size in Table 8. The numbers presented in this table are the number of occurrences of Adv-P-Det and P-Adv-Det combinations found in the database.

The change in preference from Adv-P-Det order to P-Adv-Det does not appear to coincide with changes elsewhere in the grammar, such as the possibility of preposition stranding or the like. The original preference two centuries ago for Adv-P-Det order mirrors a similar preference among focus

\footnotetext{
${ }^{14}$ In particular, Henny Klein, Ton van der Wouden, and Frans Zwarts.
} 
Table 8 Approximative adverbs inside and outside PPs

\begin{tabular}{llllll}
\hline Period & $1600-1800$ & $1800-1900$ & $1900-1950$ & $1950-2000$ & $2000-2005$ \\
\hline Adv-P-Det & 30 & 67 & 46 & 47 & 23 \\
P-Adv-Det & 5 & 45 & 70 & 116 & 143 \\
\hline
\end{tabular}

adverbs. Our observation that focus particles in Dutch prefer to precede rather than to follow prepositions may thus very well represent an early stage in grammatical change. If this change will eventually affect adverbs acrossthe-board, we expect the dispreference for focus particles in PP-internal position to become weaker over time. As a result, we expect Dutch to become more similar to English. At the moment, these conclusions must be viewed as speculative, given that a full-scale diachronic investigation of Dutch focus particles has not been conducted yet. If the change noted above in connection with approximative adverbs is really related to changes involving focus particles, we must view the change in question as being lexically diffuse, involving differences in onset and perhaps also speed of change between focus and approximative adverbs. Clearly, further study is needed to clarify these possibilities.

In Sect. 3, we established a clear pattern of preferences of prepositions in English, Dutch, and German. In the next section we suggest a possible explanation for this pattern.

\section{Constraints on the placement of focus adverbs}

The placement of focus adverbs in English has some mysterious aspects. For instance, when there is narrow focus on the direct object, nonetheless the preferred position for focus adverbs is the preverbal position (21b), even though the postverbal position (21a) has the advantage of being unambiguously associated with narrow focus on the object.

(21) a. Jane smoked only the cigars.

b. Jane only smoked the cigars.

We suspect that this peculiar behaviour of English is related to Stowell's (1981) adjacency requirement for Case assignment, which rules out adverbs intervening between verbs and their direct objects, cf.:

(22) a. *Jane smoked always the cigars.

b. Jane always smoked the cigars.

While focus adverbs enjoy a special status among adverbs because they can be adjoined to phrasal projections, the interruption of verb-object sequences is 
still dispreferred. For instance, Google counted 1,060 instances of the string only smoked the, compared to a meagre 117 of the string smoked only the.

What can be the explanation for this dispreference? We suggest that the dispreference might be due to the interaction between two general constraints on word order: on the one hand Stowell's requirement that direct objects must appear adjacent to their verb, and on the other hand the constraint that focus adverbs be adjoined to the phrase in focus:

Adjacency(DO-V): Direct objects must appear adjacent to their verb.

Mark Focus Syntactically: Focus adverbs must be adjoined to their focus.

The constraint in (23) is the violable counterpart of Stowell's requirement. Because the input to optimization in syntax is assumed to consist of a lexical head plus its argument structure (Grimshaw, 1997), the purpose of this constraint is not to identify the argument of the verb (which is already given in the input), but rather to determine the surface positions of the verb and its object. The second constraint is a stronger version of the generally accepted constraint that focus adverbs must c-command their focus. It expresses a preference for focus adverbs to unambiguously mark the phrase in focus by means of their syntactic position. It thus prohibits cases where the phrase in focus is not identical to the c-command domain of the focus adverb but is contained within this c-command domain. Note that it does allow for both left-adjunction and right-adjunction of the focus adverb to the XP in focus.

Crucially, a conflict arises between these two word order constraints if focus is on the direct object. In this situation, the resulting word order violates the focus marking constraint if the focus adverb is placed in preverbal position, because in this case the focus adverb is not attached to the phrase in focus but rather to a larger structure containing the phrase in focus. On the other hand, if the focus adverb is placed in postverbal position, the resulting word order violates the adjacency constraint because the direct object is now separated from the verb by an intervening focus adverb. The conflict between these two constraints can be resolved under an OT approach (e.g., Prince \& Smolensky, 2004) to syntax. In OT, conflicts between constraints are resolved by allowing one constraint to take priority over another constraint. Under this approach, the focus adverb is predicted to occur in either preverbal or postverbal position, depending on the relative strength of the two constraints. If the adjacency constraint is stronger than the constraint on focus marking, the focus adverb will be placed in preverbal position. If, on the other hand, the constraint on focus marking is stronger than the adjacency constraint, the focus adverb will occur postverbally. In English, there is a clear preference for the focus adverb to occur preverbally. This suggests that in English the adjacency constraint is stronger than the focus marking constraint. Nevertheless, the focus marking constraint also has its effect, since satisfying this constraint results in the acceptability of (21a). In contrast, sentence (22a) is unacceptable because the adjacency constraint is violated without there being any reason 
for violating it. Such a reason could be that violation of the adjacency constraint allows another constraint to be satisfied. In German and Dutch, the requirement of adjacency between a verb and its direct object must be weaker than in English, because German and Dutch allow the direct object to be separated from its verb by sentential adverbs in scrambling constructions.

According to Stowell's adjacency requirement, direct objects must occur adjacent to their verb to be able to receive case. We suggest that a similar constraint applies to prepositions and their prepositional object. That is, prepositional objects should in principle occur adjacent to their preposition:

$$
\begin{aligned}
& \text { Adjacency(DP-P): Prepositional objects must appear adjacent to their } \\
& \text { preposition. }
\end{aligned}
$$

As in the case of the adjacency constraint in (23), the purpose of this constraint is to determine the surface positions of the preposition and its object. What is the object of the preposition is already given in the input and need not be determined. As a consequence, this constraint is violated if a focus particle intervenes between the preposition and its object. No analysis is possible according to which the focus particle together with the DP is interpreted as the object of the preposition. Note that in a fully-worked-out OT account of the placement of focus particles, this constraint as well as our reformulation of Stowell's requirement as the constraint in (23) might preferably be formulated in terms of alignment constraints. However, for the sake of simplicity we will stick to the present formulation.

Again, this adjacency constraint is in potential conflict with the constraint on syntactic focus marking. If focus is on the prepositional object, and if the adjacency constraint in (25) is the stronger constraint, the focus adverb precedes the preposition. On the other hand, if the focus marking constraint is strongest, the focus adverb follows the preposition. However, whereas in German and Dutch the adjacency constraint in (23) is weaker than the focus marking constraint in (24), in these languages the adjacency constraint in (25) must be stronger than the focus marking constraint in (24). Since German and, to a somewhat lesser extent, Dutch strongly prefer the focus adverb to precede the preposition, this suggests that a violation of the focus marking constraint is less serious than a violation of the adjacency constraint for prepositions in these languages. So in fact there seems to be an entire family of adjacency constraints, the strength of which varies with the particular combination of lexical elements. This provides an explanation for the substantial variation we observed with respect to PP-internal focus particles, which was due to, among other factors, the particular preposition and the particular determiner introducing the DP complement of the preposition.

Independent motivation for the strong collocation between prepositions and their prepositional objects in German is the fact that in German prepositions and the following determiner can be contracted: in the prepositional phrase im Hause 'in the house' the preposition in 'in' and the determiner dem 'the(DAT)' have been contracted. 
Another indication that the placement of focus particles follows from the interaction between general constraints on word order, rather than being determined by issues of scope and interpretation, is the observation that the same preferences that occur with focus adverbs also occur with correlative conjunctions (on the properties of the latter in Dutch, cf., e.g., Hendriks, 2004; Neijt, 1979). Correlative conjunctions such as Dutch zowel 'both' (which appears in the fixed combination zowel-als 'both-and') introduce the first conjunct of a coordinate structure headed by als. However, zowel sometimes shows a tendency to precede rather than follow a preposition, even if this results in the coordination of unlike categories (such as the PP boven Groot-Brittannië and the DP de Verenigde Staten in (26) below, taken from the Eindhoven corpus):

(26) Zowel boven Groot-Brittannië als de Verenigde Staten sprong u both above Great.Britain and the United States jumped you met een parachute uit een vliegtuig. with a parachute out a plane

'Both above Great Britain and above the United States you jumped from a plane with a parachute.'

Because correlative conjunctions do not have quantificational properties, the positional preference is not related to scope. Moreover, the similarity between focus adverbs and correlative conjunctions suggests that the constraint which forces focus adverbs to occur dislocated from their focus is not particular to focus adverbs. Rather, it is a general constraint requiring adjacency between the preposition and its prepositional object. In effect, this constraint is violated by any intervening material, not only by an intervening focus adverb.

Standard OT does not predict any variation with respect to the placement of focus adverbs. Either the focus adverb precedes the preposition, or the focus adverb follows the preposition, depending on the relative ordering of the constraints. However, we found mere tendencies rather than absolute possibilities with respect to the placement of focus adverbs inside prepositional phrases. Consequently, the observations discussed in this article seem best compatible with a particular variant of OT, namely stochastic OT (Boersma, 1998; Boersma \& Hayes, 2001). According to stochastic OT, linguistic constraints have a ranking value on a continuous scale of real numbers rather than on a discrete ordinal scale. In addition, their ranking is perturbated by adding to its ranking value a random value drawn from a normal distribution. This gives rise to a certain amount of optionality and variation. Stochastic OT models have been shown to account for variation within and across languages, including diachronic change (see Bresnan, Dingare, \& Manning, 2001; Clark, 2004; Jäger, 2004). If one of two conflicting word order constraints is slightly stronger than the other, the result is a clear preference for one of the two word orders, but at the same time it results in a certain amount of variation between the two word orders. As we argued, this is exactly what happens with the constraints influencing the placement of focus adverbs. 
If the analysis we suggest is correct, the placement of focus adverbs in English, German, and Dutch should receive a similar explanation. That is, despite the apparent differences between the three languages, the placement of focus particles should be subject to the same set of constraints on word order. The only difference between the three languages would be the relative strength of the proposed constraints. If the constraint requiring adjacency between a preposition and its object is stronger in German than in Dutch, as compared to the constraint on focus marking, and again it is stronger in Dutch than in English, this should account for the observed differences between the three languages. This hypothesis could be tested in computer simulations which employ the Gradual Learning Algorithm (Boersma \& Hayes, 2001). In the same way, our assumptions with respect to the change in position of approximating adverbs in Dutch over several centuries could be tested.

\section{Conclusions}

Our survey of four key analyses of focus particles revealed that there is considerable disagreement on the possibility of PP-internal and DP-internal focus particles in languages such as Dutch, English, and German. This disagreement is partly due to disagreement on acceptability judgements. Although many have claimed that English allows PP- and DP-internal focus particles (e.g., Bayer, 1996; Büring \& Hartmann, 2001), others (e.g., Rooth, 1985; Taglicht, 1984) have questioned this possibility on the basis of differing acceptability judgements. On the other hand, the general consensus on German and Dutch seems to be that PP- and DP-internal focus particles are impossible (Bayer, 1996; Büring \& Hartmann, 2001; Jacobs, 1983), although this claim, too, has been disputed on the basis of empirical evidence (Hoeksema, 1999; Hoeksema \& Zwarts, 1991). To resolve some of the issues regarding focus particles, we performed a large-scale corpus investigation.

Corpus data showed that PP-internal focus particles are a genuine option in Dutch. However, the corpus also provided evidence for the claim that there is a strong dispreference for focus particles to follow a preposition. In German, this dispreference is even stronger than in Dutch, although PP-internal focus particles do not seem to be completely ruled out in German either. In the light of these empirical facts, the analyses of Jacobs (1983) and Büring and Hartmann (2001) cannot be maintained. Whether Bayer's (1996) analysis can be upheld depends on whether PPs actually are islands for movement in German and Dutch. If corpus research should show that the impossibility of preposition stranding in these languages is in fact a dispreference similar to that found with PP-internal focus particles, this would lend support to Bayer's analysis. However, our discussion of the change in preference with approximative adverbs suggests that this possibility is unlikely. On the other hand, if corpus research should reveal that preposition stranding is truly impossible in these languages, Bayer would have to provide an explanation for the differ- 
ences between preposition stranding and focus particles in PP-internal position in German and Dutch.

Notwithstanding the general dispreference for PP-internal focus particles in Dutch and German, substantial variation can be observed. This variation turned out to be due to several factors: lexical variation among prepositions and focus particles, variation among the determiners introducing the DP complement of the preposition, as well as syntactic factors. Interestingly, although English is much more liberal with respect to the possibility of PPinternal focus particles, the patterns of variation found in English were similar to those found in Dutch and German. Although Rooth's (1985) semantic account correctly predicts PP-internal focus particles in principle to be possible in the three languages, his analysis does not provide an explanation for the observed (dis)preferences. We speculated that the dispreference for PP-internal focus particles in Dutch may gradually weaken over time as a consequence of a more general change in preference in Dutch with regard to adverbs, from PP-external to PP-internal combinations. As a result, Dutch may become more similar to English regarding the distribution of focus particles.

Acknowledgements This paper emerged from a discussion on focus particles at a meeting of the Semantics Club Groningen, October 22, 2002. The authors thank Susi Wurmbrand and three anonymous reviewers for helpful comments and suggestions. Petra Hendriks gratefully acknowledges the Netherlands Organisation for Scientific Research, NWO (grant no. 015.001.103).

\section{References}

Barbiers, S. (2003a). Focus Particle Doubling and V2. Paper presented at the TIN-dag, Utrecht, Netherlands, February 1, 2003.

Barbiers, S. (2003b). Generalized Focus Particle Doubling. Paper presented at CGSW, Durham, UK, September 2003.

Bayer, J. (1990). Interpretive Islands: Evidence for connectedness and global harmony in Logical Form. In: G. Grewendorf \& W. Sternefeld (Eds.), Scrambling and barriers. Amsterdam: Benjamins.

Bayer, J. (1996). Directionality and logical form: On the scope of focusing particles and WH-in-situ. Dordrecht: Kluwer.

Behaghel, O. (1932). Deutsche syntax, Vol. 4. Heidelberg: Winter Verlag.

Boersma, P. (1998). Functional phonology: Formalizing the interactions between articulatory and perceptual drives. Ph.D. Dissertation, University of Amsterdam.

Boersma, P. \& Hayes, B. (2001). Empirical tests of the Gradual Learning Algorithm. Linguistic Inquiry, 32, 45-86.

Bresnan, J., Dingare, S., \& Manning C. D. (2001). Soft constraints mirror hard constraints: Voice and person in English and Lummi. In: M. Butt \& T.H. King (Eds.), Proceedings of the LFG01 Conference, CSLI Publications.

Büring, D. \& Hartmann, K. (2001). The syntax and semantics of focus sensitive particles in German. Natural Language and Linguistic Theory, 19, 229-281.

Chomsky, N. (1976). Conditions on rules of grammar. Linguistic Analysis, 2, 303-352.

Clark, B. Z. (2004). A stochastic optimality theory approach to syntactic change. Dissertation, Stanford University.

Grimshaw, J. (1997). Projection, heads, and optimality. Linguistic Inquiry, 28, 373-422. 
Hendriks, P. (2004). Either, both and neither in coordinate structures. In: A. ter Meulen \& W. Abraham (Eds.), The composition of meaning: From lexeme to discourse (pp. 115-138). Amsterdam: John Benjamins.

Hoeksema, J. (1989). Only in Dutch: a comparison of three adverbs. Penn Review of Linguistics, $13,106-121$.

Hoeksema, J. (1999). Review of Josef Bayer, Directionality and Logical Form. Journal of Linguistics, 35, 395-399.

Hoeksema, J., \& Zwarts, F. (1991). Some remarks on focus adverbs. Journal of Semantics, 8, 5170.

Jacobs, J. (1983). Fokus und Skalen: Zur Syntax und Semantik der Gradpartikeln im Deutschen. Tübingen: Niemeyer.

Jäger, G. (2004). Learning constraint sub-hierarchies. The Bidirectional Gradual Learning Algorithm. In: R. Blutner, \& H. Zeevat (Eds.), Optimality theory and pragmatics (pp. 251287). MacMillan: Palgrave.

Kayne, R. S. (2000). Parameters and universals. Oxford: Oxford University Press.

Klein, H. (1998). Adverbs of degree in Dutch and related languages. Amsterdam/ Philadelphia: John Benjamins.

König, E. (1991). The meaning of focus particles: A comparative perspective. London: Routledge.

Link, G. (1983). The logical analysis of plurals and mass terms: A lattice-theoretic approach. In: R. Bäuerle, C. Schwarze, \& A. von Stechow (Eds.), Meaning, use and interpretation of language (pp. 302-323). Berlin: De Gruyter.

Malouf, R. \& van Noord G. (2004). Wide Coverage Parsing with Stochastic Attribute Value Grammars. In: IJCNLP-04 Workshop Beyond Shallow Analyses - Formalisms and statistical modeling for deep analyses.

Neijt, A. (1979). Gapping: A contribution to sentence grammar. Dordrecht: Foris.

Prince, A., \& Smolensky, P. (2004). Optimality theory: Constraint interaction in generative grammar. Oxford: Blackwell. (distributed as unpublished manuscript, Rutgers University, New Brunswick, NJ and University of Colorado, Boulder, 1993).

Reinhart, T. (1976). The syntactic domain of anaphora. Dissertation, MIT, Cambridge, MA.

Reis, M., \& Rosengren, I. (1997). A modular approach to the grammar of additive particles: the case of German Auch. Journal of Semantics, 14(3), 237-309.

Reis, M. (2005). On the syntax of so-called focus particles in German - A reply to Büring And Hartmann 2001. Natural Language and Linguistic Theory, 23(2), 459-483.

Rooth, M. (1985). Association with focus. Dissertation, University of Massachusetts at Amherst.

Ross, J. R., \& Cooper, W. E. (1979). Like syntax. In: W. E. Cooper \& E. C. T. Walker (Eds.), Sentence processing: Psycholinguistic studies presented to Honor Merrill Garrett. Hillsdale, NJ: Lawrence Erlbaum.

Shannon, T. F. (1995). Extraposition of NP complements in Dutch and German: An empirical comparison. In: T. F. Shannon, \& J. P. Snapper (Eds.), The Berkeley Conference on Dutch Linguistics 1993 (pp. 87-116). Lanham, MD: University Press of America.

Stowell, T. (1981). Origins of phrase structure. Ph.D. Dissertation, Cambridge, MA MIT.

Taglicht, J. (1984). Message and emphasis: On focus and scope in English. London: Longman.

van der Beek, L., Bouma, G. \& van Noord, G. (2002). Een brede computationele grammatica voor het Nederlands. Nederlandse Taalkunde, 7(4), 353-374. 